\section{The Royal College of Ophthalmologists Guidelines on AMD: Executive Summary}

Eye (2013) 27, 1432; doi:10.1038/eye.2013.249

Correction to: Eye (2013) 27, 1429-1431;

doi:10.1038/eye.2013.233; published online 25 October 2013

Since the online publication of the above article, the authors have noted that the members of the AMD Guidelines Group were not included. The correct details are given below.
U Chakravarthy, M Williams and AMD Guidelines Group

\section{Contributors}

Members of the AMD Guidelines Group

Winfried Amoaku, Clare Bailey, Paul Bishop, Chris Brand, Usha Chakravarthy, Victor Chong, Susan Downes, Jennifer Evans, Andrew Lotery, Gary Rubin, John Sparrow, James Talks, Michael Williams, Cathy Yelf.

The authors would like to apologise for this error. 